\title{
Indexing Research: An Approach to Grounding Ingarden's Ontological Framework
}

\author{
John W Lamp \\ School of Information Systems, Deakin University, Geelong, Victoria \\ email: John.Lamp@deakin.edu.au \\ Simon Milton \\ Department of Information Systems, University of Melbourne, \\ Melbourne, Victoria \\ email: smilton@unimelb.edu.au
}

\begin{abstract}
Attempts to produce an adequate and long-lived subject indexing system for information systems research have failed. In this paper we seek to address this by proposing an approach by which the terms expressed in research literature, such as those in the information systems literature, can be systematically and meaningfully categorised. The approach is significant in that it draws upon rigorous and philosophically compatible bodies of work in two areas. Firstly, we draw on work addressing the nature, existence, and categorisation of literary expression found in research papers (Roman Ingarden's ontological analysis of the scientific work of art). Secondly, we draw from qualitative research methods addressing how meaningful categories can be analysed from text and related to each other (grounded theory). The resulting approach has the potential to be applied in many scientific disciplines beyond information systems, and to form the intellectual core of an information tool in e-research.
\end{abstract}

\section{Introduction}

Roman Ingarden developed a number of conceptual and methodological frameworks for ontological analysis of texts, which are documented in his books The Literary Work Of Art (1965) and The Cognition of the Literary Work Of Art (1968). While Ingarden's primary focus was on mainstream literature, he also considered scientific works along with a number of other literary forms as borderline cases of the literary work of art. We are presently involved in a project, a significant aspect of which involves the analysis of papers reporting 
information systems research in academic journals. A broader description of this project and a discussion of the rationale for using Ingarden's frameworks can be found in Lamp and Milton $(2003,2004)$.

The issue of applying Ingarden's framework to scientific works is significant because, while his work has been extensively applied to mainstream literature (e.g. Thomasson, 1996), there are no reports in the archival literature relating to developing his ontological analysis of scientific works into a technique which can then be applied more generally.

A threshold matter that must be considered at this point is whether or not articles publishing information systems research can be considered to be scientific works in the sense intended by Ingarden in his analysis. Ingarden published in Polish and German and the versions of his work that we are using are translations into English published in the Northwestern University Studies in Phenomenology and Existential Philosophy series. As Ingarden himself comments about translating scientific works 'a "good" translation is not impossible, though it may often be difficult' (Ingarden, 1968). In this context the comments of Ingarden's translators are relevant:

... it must be noted that 'scientific' is used here in a much broader sense than usual, in connection not only with the natural sciences but also with any serious field of study, just as the German wissenschaftlich is used. (Ingarden 1968)

This interpretation is confirmed by Cassell's German-English English-German Dictionary (Betteridge, 1978), which offers 'scholarly, scientific, learned' as translations of wissenschaftlich. Accordingly, it can be validly asserted that articles publishing information systems research can be considered to be scientific works in the sense intended by Ingarden.

To illustrate Ingarden's framework based on scientific works, we use Broadbent et al (1999) as our exemplar. This paper is from the journal MIS Quarterly. While MIS Quarterly is often rated as the most significant information systems journal (e.g. Peffers and Ya, 2003; Katerattanakul et al, 2003a, 2003b; Bharati and Tarasewich, 2002; Mylonopoulos and Theoharakis, 2001; Walstrom and Hargrave, 2001), the choice of this particular paper is not significant; it was chosen simply because it was conveniently at hand. To provide a context and assist with understanding the analysis in the later sections, the abstract of the paper is reproduced here:

Business process redesign (BPR) is a pervasive but challenging tool for transforming organisations. Information technology plays an important role by either enabling or constraining successful BPR. This paper explores the links between firm-wide IT infrastructure and business process change. IT infrastructure is the base foundation of the IT 
portfolio, which is shared throughout the firm in the form of reliable services, and is usually coordinated by the IS group. IT infrastructure capability includes both the technical and managerial expertise required to provide reliable physical services and extensive electronic connectivity within and outside the firm.

Exploratory case analysis of four firms (two in retail and two in petroleum) was used to understand the ways IT infrastructure contributes to success in implementing BPR. The finding was that all firms needed a basic level of IT infrastructure capability to implement BPR. The firms that had developed a higher level of IT infrastructure capabilities, before or concurrent with undertaking business process redesign, were able to implement extensive changes to their business processes over relatively short time frames. The higher level of infrastructure capability was provided in the form of (1) a set of infrastructure services that spanned organisational boundaries such as those between functions, business units, or firms, and (2) the ability of the infrastructure to reach particular constituencies inside and outside the firm to transfer information and process complex transactions.

The more extensive business process changes were more innovative and radical, crossing business and functional unit boundaries, and resulted in more significant business impact. The practical implication of the study is that before embarking on any form of BPR, managers should complete a business audit of their IT infrastructure capabilities, as these capabilities have an important impact on the speed and nature of business process change.

Examining the abstract, one can see many features that are in common with many other works in the information systems literature. Specifically, the paper considers BPR, a strategic and tactical tool in which information systems play an enabling role, it applies both qualitative and quantitative techniques, it examines complex case studies in four organisations, and it discusses many infrastructural and organisational impacts on the success of implementing BPR and associated enabling technology. Consequently, we argue that by applying Ingarden's framework to this paper we will be able to gain insight into applying the methodology to other information systems literature.

Scientific works are asserted by Ingarden to consist almost exclusively of genuine judgements (1968), the most significant ontic items of which are:

- the states of affairs described;

- schematised aspects; and

- the represented objectivities. 
In the following sections we examine the concepts in Ingarden's framework in some detail.

\section{Genuine judgements and states of affairs}

Ingarden (1968) asserts that literary works of art contain no genuine judgements, they contain quasi-judgements. The literary work of art concerns a portrayed world, in which assertions, or statements by portrayed persons, can only be considered within the context of the portrayed world. In contrast, he asserts that the role of the scientific work in the transmission of cognitive knowledge requires that its context is that of states of affairs in the real world. Consequently, because there is a real world to which judgements refer, he calls the judgements in scientific works genuine judgements.

Ingarden states that genuine judgements are assertions that may be true or false, but they lay claim to truthfulness. For example, a paper may report 'The management style of company A was undemocratic', which is a result perceived as true by that particular researcher, and yet a second researcher may report a different result. Despite their essential contradiction, both statements are genuine judgements. Ideally, genuine judgements allude to means of confirmation that may be found in experience, or are contained in literary proofs based on reasoning and written in conceptual language. Failure to provide means of confirmation weakens the paper and reduces its functional value (Ingarden, 1968). Broadbent, et al (1999) shows many examples of the first form of confirmation.

From March to September 1992, a small team further examined process approaches concurrently with a detailed study of the capabilities of the firm's current systems and infrastructure.

This quote is a genuine judgement about the efforts of the CostCo business process reengineering team, as collected by the authors of the paper; that is, it reports events actually experienced by the person reporting to the authors of the paper, and therefore claims authority based on reporting an actual contemporary experience. On the other hand, consider:

Business process redesign (BPR) is a pervasive tool for transforming organisations (Grover et al. 1993) and [is] ranked as one of the most important issues for information systems (IS) executives since the early 1990s (Brancheau et al. 1996; Index Group 1994; Watson et al. 1996).

This quote is a genuine judgement regarding the views of IS researchers on BPR; that is, it reports a state of affairs reported in the IS literature and therefore claims authority based on previous accepted research.

Genuine judgements whose authority is based on literary proofs are relatively unusual in information systems research and are not found in Broadbent et al 
(1999). An example of this form of genuine judgement is the following definition from Smith (1998):

$$
\text { DD5 } \begin{aligned}
\mathrm{OS}(x, y):=x \leq y \wedge x \neq y \wedge \exists w(w \leq y \wedge \neg \mathrm{O}(w, x) \wedge \\
\mathrm{SD}(w, x)) \wedge \neg \exists w(w \leq y \wedge \neg \mathrm{O}(w, x) \wedge \mathrm{SD}(x, w)) \\
\text { one-sidedly separability }
\end{aligned}
$$

Broadbent et al (1999) also contains questions such as those in the following extract:

Important questions to consider include:

To what extent does the firm have at least the 10 core infrastructure services (see Table 1) together with the seven boundary-crossing services in place?

What is the reach in terms of who can be seamlessly connected?

What range of services are available: only the ability to access information or the capacity to perform complex business transactions across multiple systems?

Such questions could be reworded as assertive statements, reporting evidence or argument supporting the affirmative or negative, and hence should also be considered genuine judgements (Ingarden, 1965).

\section{Schematised aspects}

Objects represented in a literary work are derived, purely intentional, objects projected by units of meaning (Ingarden, 1965). They are intentional because an author has written them with a purpose. For literary works of art, the purpose is to tell a story or generate a particular aesthetic effect; for scientific works, it is the transmission of cognitive results (Ingarden, 1965). In both cases the objects are derived, because we cannot enter the mind of the author. Finally, they are projected because it is only through language (in this case written language) that can we understand what is intended.

Consider the following extract, also from Broadbent et al (1999):

CostCo has a robust network with numerous LANs in place at its head office, in large cities, and other major sites. 'About 2,000 PC users have whatever multihost connectivity is required for their business needs We have moved from computer-centric to network-centric computing', noted the CIO. Business units utilised these networks as a basis for a new distributorship, retail and electronic funds transfer, and point of sale (EFTPOS) systems. 
This extract concerns the existence and nature of the network in place at CostCo - it describes one aspect of CostCo. The physical nature of the network is described along with the scope and purpose of the network and the attitude of management towards its use. An outline of the functionality offered by the network in place is also described.

However, what is represented by this extract does not stop at the network but extends further to linkages provided for EFTPOS, the retail activities of CostCo and other related activities, and the general management policy framework within which the specific network policy lies, even though none of this is directly given to us. This is also typical of scientific and other literary works because there is seldom enough room to completely describe a state of affairs. Equally, this description does not delve into the details of the precise networking protocols, hardware, operational requirements and other minutiae of CostCo's network. If this depth of analysis were provided, then the extract would no longer be talking about the network, but of the components of the network and how it was managed.

For these reasons, literary works necessarily consist of incomplete descriptions, termed schematised aspects, which contain fulfilled (explicitly described) components and unfulfilled components that, while not explicitly described, may not be indeterminate. The reader may fill these out from aspects held in readiness from previous experiences. Prompting the most appropriate aspect is influenced by the word choice and represented objectivities selected by the author. For example, by using two words identical in meaning, but different in word sound, the reader may be influenced towards different aspects (Ingarden, 1965). Substituting 'many' for 'numerous' in the preceding quote does not alter its meaning, but may influence the reader's choice of aspects between perceiving CostCo's LANs as an unordered collection or as an ordered and therefore managed collection.

Because these aspects are based in perception, and aspects of the same object that are experienced by different individuals must differ in various respects, it is not possible for the reader to actualise with complete accuracy the same aspects intended by the author (Ingarden, 1965). The degree of this type of perceptual error in a scientific work is reduced, as schematised aspects are intended only for assistance in the transmission of cognitive knowledge. The use of decorative or evocative aspects is unnecessary, and may hinder the essential aim of a scientific work - accurately transferring knowledge as intended by the author (Ingarden, 1965).

\section{Represented objectivities}

A literary work of art describes people, animals, lands, houses and other items. This represented world is not the real world - the represented objects within 
it may not exist in the real world or may behave differently to such objects within the real world. As a reader reads a passage of words and phrases (meaning units) containing a represented objectivity, he or she relates directly to the state of affairs that the represented objectivity is helping to clarify. Consequently, a particular represented objectivity within a scientific literary work causes us to direct ourselves to corresponding states of affairs. Because we are dealing with a scientific work rather than a literary work of art, this directional ray passes through the content of these represented objectivities so that they refer to objectively existing states of affairs, or to objects contained within them rather than to some fictional creation (Ingarden, 1965). See Figure 1 for a representation of this. It is through this directional meaning ray that the represented objectivities claim to determine objects in the real world as they are in themselves and thereby claim to be genuine judgements (Ingarden, 1968).

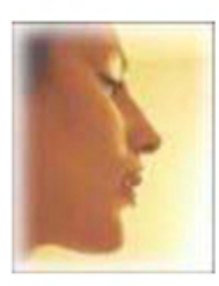

Reader

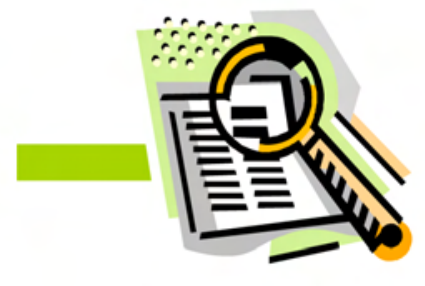

Represented objectivity

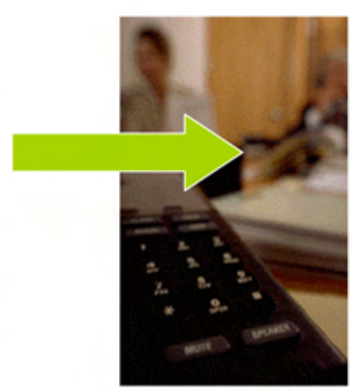

State of affairs, or object within a state of affairs

\section{Figure 1: The directional meaning ray.}

In a scientific work, clarity in writing directly affects the transparency of represented objectivities. Where readers have difficulty in relating to the state of affairs beyond the text then the represented objectivities are not 'clear'. Ideally the represented objectivities are transparent; that is, the way that they inform the reader regarding the particular state of affairs under discussion requires little conscious interpretation. In the extract above, the IT infrastructure (the state of affairs being discussed) is correlated with the represented objectivities 'computer-centric' and 'network-centric'. For readers of MIS Quarterly, these would be readily understood concepts and hence transparent. It should be noted that if that was not the case, and the authors went on to define the concepts, then the concepts would become states of affairs for which other, hopefully more transparent, represented objectivities could be found to describe them. In the absence of such explanation from the authors, the reader re-reads the sentences, concentrating on the word meanings and syntactic interconnections until the represented objectivities become clear and unequivocal (Ingarden, 1968). 
Summarising, any scientific work will contain genuine judgements, states of affairs, schematised aspects, and represented objectivities. Effective subject indexing in any academic field requires the terms in these ontic categories be identified and the relations between them defined. The terms in these categories are meaningful to some group(s) of people and form the basis of the subject indexing. Clearly, there are potentially scores of specific terms that fit within each of the identified categories. Further, the relative importance of each term is not evident a priori. Thus, in order to operationalise Ingarden's high-level categories, we need an approach that captures the essence of the activity. We seek terms that (a) are meaningful to a group of people, (b) exhibit cognitive economy (Rosch, 1978), and (c) are discovered through a process that is repeatable. The principle of cognitive economy is that categorisation should provide a great deal of information about the item categorised with only minimal cognitive resources expended. In the following section we outline an approach based on both Ingarden's categories and the grounded theory method.

\section{Developing a technique}

In order to effectively apply Ingarden's framework, a technique must be developed for its application to the items being analysed. Information systems practice requires documenting and preparing specifications based on interviews with clients and textual material supplied by clients. Accordingly, information systems research has concerned itself with techniques for analysing text. One technique that has attracted a deal of interest is the grounded theory method (Glaser and Strauss, 1967). In this paper we propose to look at the use of this method for coding items in a text document and how this can be used for the identification and refinement of the categories of ontic items described by Ingarden.

\section{Grounded theory method and its use in information systems}

The grounded theory method provides a logically consistent set of data collection and analysis procedures that can be used in textual analysis. The original aim of the grounded theory method was to develop a research methodology that would systematically derive theories about human behaviour from empirical data. The grounded theory method seeks to discover what is going on. Typically, it is applied to texts obtained by interview, observation or other data collection methods. Explicit in the use of grounded theory is data collection from participants who may have different views of the phenomena being studied, and which must be accommodated in the development of theory. There is an apparent resonance here with Ingarden's concepts of schematised aspects held in readiness, and transparency of represented objectivities varying between individuals. 
Since its original announcement, grounded theory has become an accepted qualitative research technique in information systems (Urquhart, 2001). Its adoption has probably been assisted by its originators' assertions that it is 'not bound by either discipline or data collection' (Glaser, 1992). Grounded theory is concerned with the identification of categories, or properties of categories, as a major issue (Glaser, 1992). While grounded theory was described as having emerged from symbolic interactionism, Annells (1996) classified it as being ontologically based in critical realism. Glaser and Strauss (1967) state 'our position is not logical; it is phenomenological'. Grounded theory can therefore be considered to be framed from an ontological perspective that is not in conflict with the realism of Ingarden.

At this point it should be noted that, while we are seeking to develop a methodology where all components share a consistent philosophical perspective, the content of the papers being analysed would not be limited to this perspective. The nature of the philosophical perspective used and reported on by researchers in the papers studied would be a value assigned to a category in our analysis.

Reviews and examples of the use of grounded theory in information systems research can be found in Calloway and Ariav (1991), Pidgeon et al (1991), Hughes and Howcroft (2000), Urquhart (2001), Fernandez (2004) and Lings and Lundell (2005). Hughes and Howcroft (2000) review a number of uses and adaptations of the grounded theory method by information systems researchers. After considerable discussion of the implications of the way in which information systems researchers have applied grounded theory, and the views of the originators, Strauss and Corbin, Hughes and Howcroft (2000) argue against the rigid application of the grounded theory method in practice. They also note that '[i]f the research community is to mature then it would be of far greater benefit to tell the story as it were, and this should include the researcher's perspective, actual use of the method, and a reflective evaluation'. Further, they assert that 'the adoption and diffusion of the method should be welcomed since it represents its usefulness as a pragmatic tool for research'.

Urquhart (2001) provides considerable detail regarding an instance of using grounded theory method to examine client - analyst interaction and behaviour, and also lists a number of IS researchers using the grounded theory method. One instance where grounded theory was used (Orlikowski, 1993) received MISQ's Best Paper Award in 1993. Fernandez (2004) also provides a background discussion of the grounded theory method, plus a report of the experience of using the method. He agrees with many of the points made by Urquhart (2001). Fernandez (2004) employed the software package ATLAS.ti to assist with his analysis and makes some cautionary points about the limitations and negative aspects of software assisted coding, and in particular that the potential for automatic coding (e.g. coding all occurrences of a word or phrase) can have a 
negative effect in obscuring discovery by the researcher. This confirms the cautions given by Glaser about hiring coders and the use of automated systems, which remove the analyst from close contact with their data (Glaser 1978).

At this point it should be noted that grounded theory has come to include two divergent approaches. We now distinguish between those two approaches and the degree to which they suit the needs of this research.

In 1992 Barney Glaser published Emergence vs. Forcing: Basics of Grounded Theory Analysis (Glaser, 1992) in which he set out a comprehensive and vigorous attack on the contents of a 1990 book written by his original collaborator, Anselm Strauss, and Strauss' research partner, Juliet Corbin (Strauss and Corbin, 1990). Glaser considered their book 'distorts and misconceives grounded theory method, while engaging in a gross neglect of $90 \%$ of its important ideas' (Glaser 1992). In the years since this conflict, researchers have found both approaches useful since their different emphases make them more or less appropriate in specific research settings (Fernandez, 2004). The Glaserian approach is described as abstract conceptualisation, and the Straussian approach as full-description (Fernandez, 2004). This difference relates to a disagreement regarding the unit of analysis. The Straussian approach emphasises word by word analysis (Strauss and Corbin, 1990), while the Glaserian approach deals with units of meaning at the line or sentence level (Glaser, 1978). Strauss and Corbin give an example (1990) of taking an hour to discuss what an individual meant by the word 'once'.

Our purpose in undertaking this analysis is to discover what research is being reported in information systems journal papers. As described above, the purpose of such papers is the transmission of cognitive knowledge, a concomitant of which is for the papers to be written using represented objectivities that are, ideally, transparent. In this case then, there should be little need for extensive analysis of individual words and their possible meanings. Our aim is to abstract, rather than commentate. The Glaserian approach therefore appears to be more appropriate in this study.

Another significant difference in the two approaches to grounded theory, for our purposes, is the method of coding data. The Strauss and Corbin method requires that all data be coded against a single coding family - context, conditions, action/interactional strategies, intervening conditions and consequences. The Strauss and Corbin coding family is, however, clearly inappropriate for ontological analysis. This coding family was a variation of only one of eighteen coding families proposed as a significant part of the book Theoretical Sensitivity by Glaser (1978). Several of those coding families refer to ontological and mereological concepts (e.g. The Dimension Family, The Type Family, The Theoretical Family and The Conceptual Ordering Family — see Table 1). The list presented by Glaser is inclusive rather than exhaustive, and it is clearly intended that researchers using this method could derive their own 
coding families (Glaser, 1978) and this occurs in practice (Urquhart, 2001). Glaser expanded on his original list of coding families in two later books (Glaser, 1998, 2005).

$\begin{array}{ll}\text { Coding Family } & \text { Categories } \\ \text { The Dimension Family } & \begin{array}{l}\text { dimensions, elements, division, piece of, properties of, facet, slice, } \\ \text { sector, portion, segment, part, aspect, section } \\ \text { type, form, kinds, styles, classes, genre } \\ \text { parsimony, scope, integration, density, conceptual level, relationship } \\ \text { to data, relationship to other theory, clarity, fit, relevance, modifiability, } \\ \text { utility, condensability, inductive-deductive balance and inter-feeding, } \\ \text { degree of, multivariate structure, use of theoretical codes, interpretive, } \\ \text { explanatory and predictive power, and so forth } \\ \text { The Theoretical Family } \\ \text { achievement orientation, institutional goal, organisational value, personal } \\ \text { motivation. }\end{array}\end{array}$

Table 1: Selected examples of coding families (Glaser, 1978).

We propose to use Ingarden's ontological categories, defined in his framework, as the basis of a coding family for the grounded theory method coding technique. Further categories dealing with matters relating to publication, other than what is contained within the papers themselves (time to publication, reviewing status, intellectual property status) and which were suggested in Lamp (2002), may be added.

It should be noted that while this is not fully in accord with either the Glaserian or Straussian approaches, it draws on aspects of both. The unit of analysis and aim of conceptualisation tend towards the Glaserian approach. The use of a predetermined, rather than emergent, coding family is a Straussian feature, but the coding family is not that prescribed by Strauss. For the purposes of this research, we are seeking a technique that can be applied to discovering concepts within scientific works, and which is philosophically compatible with Ingarden's framework. The coding technique employed in grounded theory would appear to offer this, but we do not claim that what we are undertaking is grounded theory since it is not in accord with either the Glaserian or Straussian approaches. We appropriate the coding technique from grounded theory and adapt it to the ontological analysis of text.

\section{The coding process: foundations of the technique}

The process for coding where abstract conceptualisation is sought can be considered to consist of two phases: substantive coding and theoretical coding. Although described here sequentially, they are not executed in this way.

Substantive coding itself consists of two phases: open coding and selective coding. In open coding the analyst aims to 'generate an emergent set of categories and their properties which fit, work and are relevant for integrating into a theory' (Glaser, 1978). Units of meaning are examined and coded against as many categories as may fit. New categories emerge, and new units of meaning fit 
existing categories. In undertaking open coding the analyst considers three questions (Glaser, 1978):

- What is this data a study of?

- To what category or property of a category, or to what part of the emerging theory, does this incident relate?

- What is actually happening in the data?

The first question serves to remind the analyst that the data may not match any preconceptions held by the researcher. The second question serves to remind the analyst to consider codes already used. The third question serves to remind the analyst to consider whether a particular code might be a core category.

Selective coding occurs when the analyst identifies core categories and limits coding to 'those variables that relate to the core variable in sufficiently significant ways to be used in a parsimonious theory' (Glaser, 1978).

Theoretical coding uses the coding families, in our instance based on Ingarden's ontological categories, to ensure that the analyst works at the conceptual level, writing about concepts and interrelations, rather than being bogged down in the data. The coding families assist in ensuring that the analyst has not overlooked the dimensions of a particular approach to understanding the data. Coding continues until the main concern of the research can be accounted for and further coding fails to add significant value in categories or properties. At this point theoretical saturation is deemed to have been achieved.

\section{Substantive theory: the product of the technique}

It should be noted that while the description has necessarily been presented as a sequential set of steps, it is by no means this simple. Glaser (1998 cit Fernandez, 2004) describes it as a method that 'happens sequentially, subsequently, simultaneously, serendipitously and scheduled'. A model of the grounded theory method proposed by Fernandez (2004) is shown in Figure 2, and demonstrates this complexity. A detailed explanation of the Fernandez model is, however, beyond the scope of this paper.

Analysts applying this technique will use memos and other tools to aid the abstraction process and to provide a trail of decisions made while applying the technique. The output is expected to be a web of terms linked with high level categories. The terms will aid searching and be based on meaningful concepts that have a relationship with the texts making up the relevant body of work.

Two questions automatically arise. First, what is the group for whom the texts are meaningful? Second, how durable is the categorial scheme produced? Recall that we are interested in categorising scientific works based on the terms and concepts that exist in the work. Thus, we address these questions in that context. 


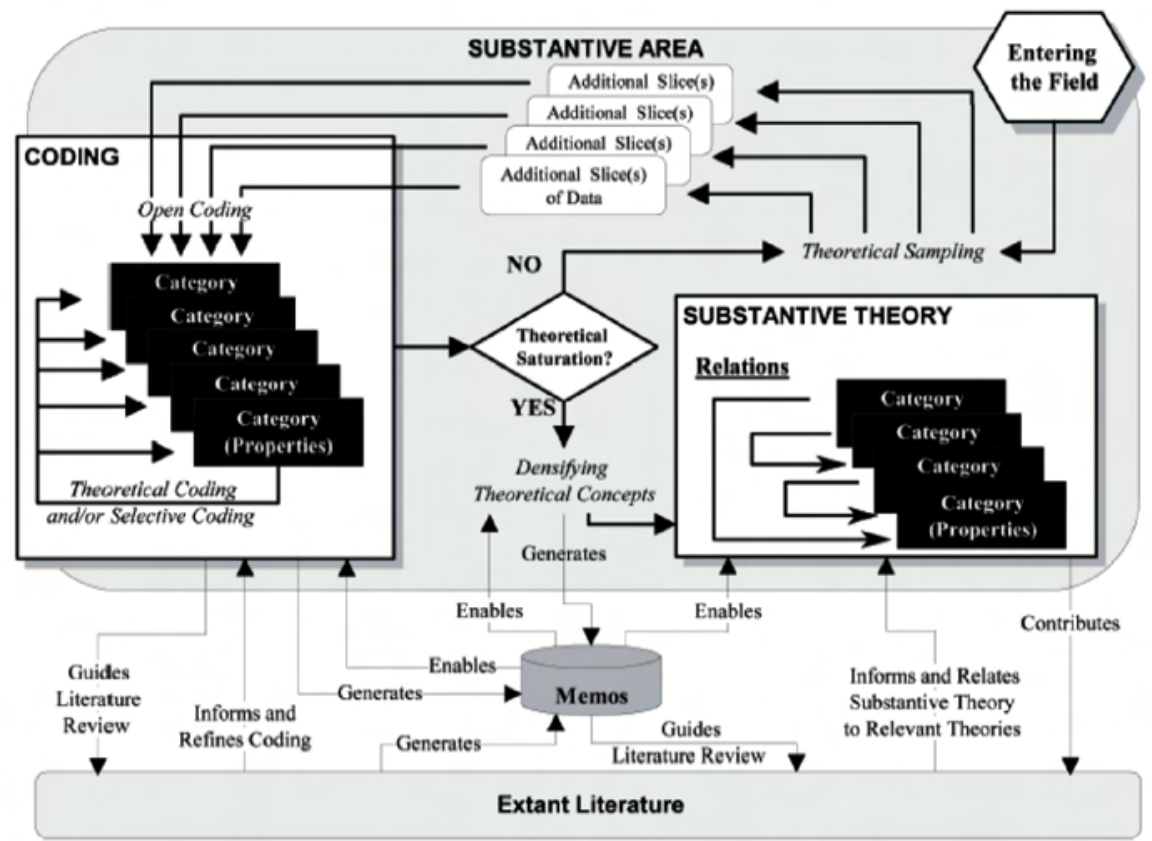

Figure 2: Grounded theory research model (Fernandez, 2004).

Regarding the first question, within a readership there may be several distinct communities of practice each of which brings different perspectives to reading the same works. The major influences are the different unfulfilled schematised aspects held in readiness by the readers from these groups. To adequately support such a heterogeneous readership, an application of the technique is required for each group. This would provide a consistent analysis reflecting the different perspectives of the readers. It could begin to capture the diversity of perspectives that exist in information systems. This is significant because it is accepted that the nature and scope of the information systems domain are diverse; the approaches to researching information systems are diverse; the approaches to teaching information systems are diverse, and there is a lack of any single clear theoretical basis underlying the study of information systems (Lamp and Milton, 2004).

With the second question, one can say that as disciplines mature and research progresses, our needs and readings of scientific works will change. For example, early theories about the structure of atoms are now largely historic and no longer have the currency they had when first published in the late nineteenth century. Clearly, however, the work itself does not change. What changes is the context of research and research theory, and also the needs and goals of the readership. Thus, the technique will need to be periodically reapplied to maintain durability. 
Nevertheless, we can say that the approach is theoretically feasible. We say this because, firstly, we have the basis of a coding family based on a sound ontological theory of research texts. Secondly, we have a methodical well-respected qualitative research method designed to meaningfully analyse text to produce conceptual categories. Together, we therefore have an approach designed to produce terms (categories) that are meaningful, emergent, and relate to high-level ontological categories for research texts.

\section{Conclusions}

The motivation for this paper was the desire to undertake an ontological analysis of information systems research literature. The product of this analysis would constitute the starting point for a categorial scheme for that domain. In his books The Literary Work of Art (1965) and The Cognition of the Literary Work of Art (1968), Roman Ingarden developed a framework from a comprehensive high level ontological analysis of literary work, including scientific works. Our examination of the research literature failed to identify any efforts to develop a tool with which to rigorously apply his framework to scientific works and this paper has attempted to address that lack. Techniques from the grounded theory method have therefore been adapted to work with Ingarden's framework.

The grounded theory method and the adaptation of this method to information systems research has been successful over a number of years. The grounded theory method was considered appropriate in the context of the research discussed in this paper due to its similar philosophical heritage compared to Ingarden's ontological framework. They are both from the realist tradition and share assumptions about the world and the ways in which it may be understood. Importantly for this research, they both explicitly provide for the accommodation of differences in perception of states of affairs by individuals. The proposed tool therefore conforms to the definition of a method as a 'coherent and systematic approach, based on a particular philosophy' (Fitzgerald et al, 2002 cit Lings and Lundell, 2005).

The adaptation of the grounded theory method is expected to provide a number of additional benefits. The application of the method may be novel, but the method itself is approaching its $40^{\text {th }}$ anniversary and, since it has had a presence in the information systems literature for the past 15 years, it should not be unfamiliar to information systems researchers. This last point is seen as significant because we see this tool as having applications beyond the immediate project for which we are developing it.

The use of this tool by a number of researchers for the purpose of this project would provide a consistent analysis that would reflect the intentionality of the researchers using it. This could begin to capture the diversity of perspectives that exists in information systems. 
The tool may also be applicable for e-research in other interdisciplinary subject domains such as health informatics as well as other forms of literature intended for transmission of cognitive knowledge in the same way as scientific works (e.g. systems and user manuals, requirements specifications etc). Journal editorial boards could use it from time to time as a check on whether what was being published actually reflected their stated aims and scope.

What remains is to see if the approach is practically feasible. Hence, the next step is to apply the approach to a significant sample of papers from the top five information systems journals. We will then be able to comment on the practicality of the approach rather than simply addressing its theoretical feasibility, as we have done here.

\section{References}

Annells, M. 1996, 'Grounded theory method: Philosophical perspectives, paradigm of inquiry, and postmodernism', Qualitative Health Research, vol. 6, no. 3, pp. 379-93.

Betteridge, H. 1978, Cassell's German-English English-German Dictionary, London, Cassell.

Bharati, P. and Tarasewich, P. 2002, 'Global perceptions of journals publishing e-commerce research', Communications of the ACM, vol. 45, no. 5, pp. 21-6.

Broadbent, M., Weill, P. and Clair, D. S. 1999, 'The implications of information technology infrastructure for business process redesign', MIS Quarterly, vol. 23, no. 2, pp. 159-82.

Calloway, L. J. and Ariav, G. 1991, 'Developing and using a qualitative methodology to study relationships among designers and tools', in Nissen, H.E., Klein, H. K. and Hirschheim, R. (eds), Information Systems Research: Contemporary Approaches and Emergent Traditions, Amsterdam: North Holland, pp. 175-93.

Fernandez, W. D. 2004, 'The Grounded Theory method and case study data in is research: Issues and design', in Hart, D. N. and Gregor, S. D. (eds) Information Systems Foundations: Constructing and Criticising, ANU EPress, Canberra Australia.

Fitzgerald, B., Russo, N.L. and Stolterman, E. 2002, Information Systems Development: Methods in Action, McGraw-Hill, London.

Glaser, B. 1978, Theoretical Sensitivity, Mill Valley CA, Sociology Press.

Glaser, B. 1992, Emergence vs Forcing: Basics of Grounded Theory Analysis, Mill Valley CA, Sociology Press. 
Glaser, B. 1998, Doing Grounded Theory: Issues and Discussions, Mill Valley CA, Sociology Press.

Glaser, B. 2005, The Grounded Theory Perspective III: Theoretical Coding, Mill Valley CA, Sociology Press.

Glaser, B. and Strauss A. 1967, The Discovery of Grounded Theory, New York, Aldine de Gruyter.

Hughes, J. and Howcroft D. 2000, 'Grounded Theory: Never knowingly understood', New Review of Information Systems Research, vol. 1, no. 1, pp. 181-99.

Ingarden, R. 1965, Das Literarische Kunstwerk (translated Grabowicz, G. G. 1973, The Literary Work of Art: An Investigation on the Borderlines of Ontology, Logic and Theory of Literature, Evanston, Northwestern University Press,) Max Niemeyer Verlag, Tübingen.

Ingarden, R. 1968, Vom Erkennen des Literarischen Kunstwerks (translated Crowley, R. A. and Olsen, K. R. 1973, The Cognition of the Literary Work of Art, Evanston, Northwestern University Press,) Max Niemeyer Verlag, Tübingen.

Katerattanakul, P., Han, B. and Hong, S. 2003a, 'Objective quality ranking of computing journals', Communications of the ACM, vol. 46, no. 10, pp. $111-4$.

Katerattanakul, P., Razi, M. and Kam, H. 2003b, 'IS journal rankings versus citation analysis: Consistency and concerns', Proceedings of the 9th Americas Conference on Information Systems, Tampa, Florida.

Lamp, J. W. 2002, 'IS journal categorisation' <http://lamp.infosys.deakin.edu.au/journ_cat/> Accessed 18/05/2004.

Lamp, J. W. and Milton, S. 2003, 'An exploratory study of information systems subject indexing' Proceedings of the 14th Australasian Conference on Information Systems, Perth Australia, Edith Cowan University.

Lamp, J. W. and Milton, S. 2004, 'The reality of information systems research', in Hart, D. N. and Gregor, S. D. (eds) Information Systems Foundations: Constructing and Criticising, ANU E-Press, Canberra Australia.

Lings, B. and Lundell, B. 2005, 'On the adaptation of Grounded Theory procedures: Insights from the evolution of the $2 \mathrm{G}$ method', Information Technology and People, vol. 18, no. 3, pp. 196-211.

Mylonopoulos, N. A. and Theoharakis V. 2001, 'Global perceptions of IS journals: Where is the best IS research published?', Communications of the ACM, vol. 44, no. 9, pp. 29-33. 
Orlikowski, W. J. 1993, 'CASE tools are organisational change: Investigating incremental and radical changes in systems development', MIS Quarterly, vol. 17, pp. 309-40.

Peffers, K. and Ya T. 2003, 'Identifying and evaluating the universe of outlets for information systems research: Ranking the journals', Journal of Information Technology Theory and Application, vol. 5, no. 1, pp. 63-84.

Pidgeon, N. F., Turner, B. A. and Blockley, D. I. 1991, 'The use of Grounded Theory for conceptual analysis in knowledge elicitation', International Journal of Man-Machine Studies, vol. 35, pp. 151-73.

Rosch, E. 1978, 'Principles of categorisation', in Rosh, E. and Lloyd, B. (eds), Cognition and Categorisation, Lawrence Erlbaum Associates, Hillsdale, pp. 27-48.

Smith, B. 1998, 'The basic tools of formal ontology', in Guarino, N. (ed.), Formal Ontology in Information Systems,. Amsterdam, IOS Press: 19-28.

Strauss, A. and Corbin, J. 1990, Basics of Qualitative Research, Sage, California.

Thomasson, A. L. 1996, 'Fiction and intentionality', Philosophy and Phenomenological Research, vol. 56, no. 2, pp. 277-98.

Urquhart, C. 2001, 'An encounter with grounded theory: Tackling the practical and philosophical issues', in Trauth, E. M. (ed.), Qualitative Research in IS: Issues and Trends , Hershey, Idea Group, pp. 104-40.

Walstrom, K. A. and Hargrave B. C. 2001, 'Forums for information systems scholars: III', Information and Management, vol. 39, pp. 117-24. 